\title{
Proposta de um sistema de avaliação da integração ensino e extensão: um guia para universidades públicas brasileiras
}

\author{
Proposal for an evaluating system the integration of teaching \\ and extension: a guide for brazilian public universities
}

\author{
Muriel de Oliveira Gavira ${ }^{1}$ \\ ${ }^{1}$ Universidade Estadual de Campinas |Faculdade de Ciências Aplicadas | Campinas | SP | Brasil. \\ Contato: mgfca@unicamp.br. ORCID: http://orcid.org/0000-0002-0235-5900
}

\author{
Ana Maria Nunes Gimenez ${ }^{2}$ \\ ${ }^{2}$ Universidade Estadual de Campinas | Instituto de Geociências | Campinas | SP | Brasil. Contato: \\ anamarianunesgimenez@gmail.com. ORCID: http://orcid.org/0000-0002-6187-0718 \\ Maria Beatriz Machado Bonacelli ${ }^{3}$ \\ ${ }^{3}$ Universidade Estadual de Campinas | Instituto de Geociências | Campinas | SP | Brasil. Contato: \\ biabona@unicamp.br. ORCID: http://orcid.org/0000-0003-0795-7684
}

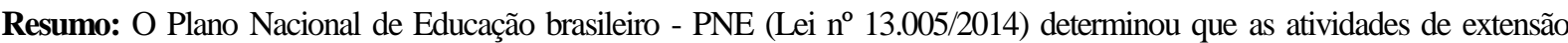 universitária devem compor, no mínimo, $10 \%$ do total da carga horária curricular dos cursos de graduação. A regulamentação dessa norma ocorreu em 2018, por meio da Resolução CNE/CES n 7 do Ministério da Educação (MEC). Esse movimento ficou conhecido como "curricularização da extensão". Entretanto, ao contrário do que ocorre no exterior, especialmente em países desenvolvidos, em que a inter-relação entre ensino e extensão já se encontra em estágio bastante avançado, no Brasil, essa relação não se dá com a mesma intensidade. Além disso, são escassos os estudos sobre indicadores e sistemas de avaliação da curricularização no Brasil. Em decorrência dessas constatações, este artigo tem como objetivo central propor um sistema de avaliação da integração ensino e extensão para as universidades públicas brasileiras. Assim, por meio de um amplo levantamento bibliográfico e documental no Brasil e no mundo, propomos um sistema de avaliação que considera sete passos e quatro conjuntos de indicadores, além de alguns pontos importantes a considerar na análise.

Palavras-chave: Integração curricular. Ensino-extensão. Ensino superior.

\begin{abstract}
The Brazilian National Education Plan - PNE (Law no 13.005 / 2014) determined that university extension activities must comprise at least $10 \%$ of the total curricular workload of undergraduate courses. The regulation of this rule occurred in 2018, through a Resolution CNE/CES n 7 of the Ministry of Education (MEC). However, differently from what happens abroad, especially in developed countries, in which the interrelationship between teaching and extension is already quite advanced, in Brazil, this relationship does not occur with the same intensity. Besides, there are few studies on indicators and evaluation systems of service learning in Brazil. As a result of these findings, this article has the central objective of proposing a system for evaluating the integration of teaching and extension for Brazilian public universities. Thus, using a wide bibliographic and documentary survey in Brazil and the world, we propose an evaluation system that considers seven steps and four sets of indicators, in addition to some important points to consider in the analysis.
\end{abstract}

Keywords: Service-Learning. Teaching-Extension. Higher education.

- Recebido em: 19 de março de 2020 • Aprovado em: 13 de maio de 2020

DOI: http://dx.doi.org/10.1590/S1414-40772020000200009

Este é um artigo publicado em acesso aberto sob uma licença Creative Commons

https://creativecommons.org/licenses/by-nc/4.0/ 


\section{Introdução}

O envolvimento das Instituições de Educação Superior (IES) com a sociedade, o que inclui a extensão universitária, pode ocorrer de diversas formas, seja em nível local/regional, nacional ou internacional, sendo vasta a literatura que discute esse tema. As interações comumente apontadas incluem desde ações de divulgação e difusão do conhecimento, até o estabelecimento de parcerias com organizações da sociedade civil, envolvimento em debates públicos, transferência tecnologia, oferecimento de serviços de saúde, iniciativas artísticas e culturais, entre outros. Essas ações representam o avanço da compreensão do papel do ensino superior na sociedade contemporânea e a necessidade de uma postura das IES mais responsiva às necessidades, problemas e demandas da sociedade.

No Brasil, as ações de integração entre o ensino e extensão (IEE) universitários são comumente chamadas de curricularização da extensão, que representa a inserção das ações de extensão nos Projetos Pedagógicos e Matrizes curriculares dos cursos de graduação ou pós-graduação (BRASIL, 2018). No exterior, por outro lado, essas ações são nomeadas de diferentes formas, tais como: "service-learning", "community-engaged courses”, “community-based learning”, “aprendizaje-servicio”, "educación experiencial”.

No país, as atividades de extensão devem compor, no mínimo, $10 \%$ do total da carga horária curricular dos cursos de graduação; entretanto, muitas IES têm enfrentado desafios para operacionalizar essa exigência, especialmente porque essa integração não constitui ainda um tema desenvolvido no Brasil. Sendo assim, este trabalho tem como objetivo a proposição de um sistema de avaliação da curricularização da extensão para as universidades públicas brasileiras.

Além desta introdução e das conclusões, este artigo apresenta outras quatro partes, que tratam, respectivamente, dos procedimentos metodológicos (seção 2), das origens da extensão universitária e dos diferentes entendimentos e estágios da curricularização (seção 3); as diferentes visões e formas de se avaliar a IEE (seção 4); a proposta de um sistema de avaliação da IEE (seção 5).

\section{Procedimentos metodológicos}

Para atingir o objetivo proposto, realizamos uma pesquisa exploratória com abordagens bibliográfica e documental. A pesquisa exploratória é justificada pois serve bem em assuntos ainda pouco explorados (COOPER; SCHINDLER, 2010), como é o caso da avaliação de ações de integração ensino e extensão nas e para as condições brasileiras. O método de análise de dados adotada foi a análise de conteúdo.

A pesquisa bibliográfica explorou as contribuições científicas de monografias e periódicos acadêmicos sobre os temas de extensão, aprendizagem em serviço e curricularização. Para tanto 
realizamos buscas, sem restrição de período e tipo de material, na base de dados “Google Scholar" usando as palavras-chave: "academic service-learning”, "aprendizaje-servicio”, "community-engaged courses", "community-based learning”, “community engagement indicators”, “community engagment assessment”, "service learning”, "service learning indicators”, "service learning assessment”, "service learning audit", “curricularização AND "indicadores", "public service courses", "educación experiencial". "curricularização AND avaliação".

Por meio da pesquisa documental coletamos materiais publicados por universidades e associações de universidades nacionais e internacionais dedicadas ao engajamento com comunidades e extensão universitária, tais como Fórum de Pró-Reitores de Extensão das Instituições Públicas de Educação Superior Brasileiras (Forproex), Australian Universities Community Engagement Alliance, Campus Compact, Engagement Scholarship Consortium, Observatorio Iberoamericano de la Ciencia, la Tecnología y la Sociedad de la OEI (OCTS), e The Carnegie Foundation for the Advancement of Teaching, entre outras. A partir desses documentos levantamos casos, estruturas analíticas (frameworks), indicadores e características desejáveis dos sistemas de avaliação. Também analisamos o quadro jurídiconormativo da IEE no Brasil.

Assim, essas abordagens permitiram conhecer o estado da arte atual da literatura que versa sobre essa temática, o arcabouço legal, bem como iniciativas de universidades e redes de universidades nacionais e internacionais.

\section{A Inclusão da extensão nos currículos universitários}

A extensão universitária surgiu em meados do século XIX como uma terceira missão, passando a servir de interface entre o mundo acadêmico, as missões ensino e pesquisa, e a sociedade. As primeiras experiências de extensão surgiram com a educação continuada de adultos em Oxford e Cambridge. Inicialmente, a extensão foi realizada por meio de palestras, em localidades carentes de instrução superior. Mais tarde, iniciou-se a estruturação de departamentos ou escolas de educação continuada (GOLDMAN, 1995; WELCH, 1973). A criação das universidades cívicas, também na Inglaterra, foi uma resposta às necessidades e demandas da Revolução Industrial, razão pela qual as primeiras foram criadas em importantes cidades industriais: Manchester (1824), Birmingham (1825), Sheffield (1828), Leeds (1831), Bristol (1876) e outras. Goddard e Vallance (2011) listam as principais ações que essas universidades estabeleceram com o seu entorno: formação de mão de obra qualificada para a indústria; apoio às atividades industriais; e oferecimento de serviços específicos à população, como os voltados à área da saúde pública. 
O modelo extensionista inglês foi replicado em instituições de diferentes países, especialmente nos Estados Unidos, onde a extensão se diferenciou e assumiu um novo formato, a extensão agrícola. Isso ocorreu com a Instituições de Concessão de Terras (Land Grant Colleges), criadas a partir de duas leis federais, os Morrill Acts (1862 e 1890), que permitiram a doação de terras (federais) para o financiamento de IES públicas que pudessem contribuir especialmente para o desenvolvimento agrícola e industrial do país (STALEY, 2013; KERR, 2005). A partir daí instituiu-se um novo modelo de IES que deveriam estabelecer fortes vínculos com a comunidade.

O processo de construção do pensamento extensionista latino-americano teve a sua origem em um movimento de reforma baseado nas aspirações dos estudantes da Universidade de Córdoba, em reação a uma universidade que eles percebiam como uma torre de marfim oligárquica e alheia à sociedade (BERNASCONI, 2008; FREITAS NETO, 2011). Angeles (1992, p. 2) comenta que tanto a universidade latino-americana do período colonial, como a republicana não "mostraram interesse em ampliar o seu âmbito para além de seus muros". A ideia de uma universidade mais participava e aberta à sociedade surge na Argentina, em 1918, a partir de um movimento liderado por estudantes, Movimento de Córdoba, cujas reivindicações podem ser sintetizadas nos seguintes pontos:

- coparticipação dos estudantes na estrutura administrativa;

- participação livre nas aulas;

- periodicidade definida e professorado livre das cátedras;

- caráter público das sessões e instâncias administrativas;

- extensão da universidade para além dos seus limites e difusão da cultural universitária;

- assistência social aos estudantes;

- autonomia universitária;

- universidade aberta ao povo (FREITAS NETO, 2011, p. 69, grifo nosso)

Os acontecimentos ocorridos em Córdoba não representaram apenas as insatisfações dos estudantes universitários argentinos, pois grande parte da irresignação dos reformistas também era compartilhada por estudantes de outros países da região (TÜNNERMANN BERNHEIM, 2003). Os reformistas expuseram, na verdade, o quadro geral das universidades latino-americanas, em que pesem as diferenças nacionais, conforme explica Tünnermann Bernheim (2003,p. 70): “a publicação do Manifesto desencadeou uma série de reivindicações e ações estudantis em quase todos os países, que colocaram a questão universitária no primeiro plano das preocupações nacionais".

Entretanto, mesmo com a expansão dos ideais reformistas o conceito de extensão que predominou durante várias décadas, salvo exceções, foi o da “entrega”, de difusão cultural, que vê a comunidade apenas como uma receptora, em um movimento unidirecional e acrítico (TÜNNERMANN BERNHEIM, 1978). Além disso, não foram estruturados programas, com objetivos bem definidos; a extensão praticamente ficou à margem das outras missões da universidade, sem quase nenhuma, ou nenhuma relação com o ensino e a pesquisa; os docentes não demonstraram interesse no seu desenvolvimento; teve pouca projeção 
nas comunidades. Essa visão assistencialista-paternalista somente seria questionada nos anos 1970, com a Segunda Conferência Latino-Americana de Extensão, realizada no México, pela União de Universidades da América Latina, em 1972 (UDUAL) (TÜNNERMANN BERNHEIM, 1978).

De qualquer forma, Conway et al. (2009) explicam que o modelo de extensão mais socialmente comprometido, que se generalizou na América Latina, teve a sua inspiração tanto no Movimento Reformista de Córdoba, como também no pensamento freireano, que fomentou a extensão crítica.

\subsection{A integração curricular da terceira missão em diferentes países: visão geral}

Os Land Grant Colleges possuem uma tradição consolidada de engajamento público, pois o recebimento de recursos federais está condicionado à realização de ensino, pesquisa e serviços à sociedade (LAND-GRANT IMPACTS, 2019). O pensamento de Ernest Boyer acerca do papel da academia na sociedade também exerceu grande influência, nos Estados Unidos, para que o engajamento assumisse uma nova forma, o service-learning, incorporando o envolvimento comunitário e cívico no currículo formal da graduação (VALLANCE, 2016).

Howard (2001), por sua vez, utiliza o termo "academic service-learning" para determinar atividades que vão além do estágio ou da prestação de um serviço à comunidade. É um modelo de aprendizagem que é concretizado pela integração do serviço comunitário ao currículo de um curso para o aprendizado acadêmico e a prática da cidadania.

Ainda nos Estados Unidos, a Carnegie Elective Community Engagement Classification, criada em 2006, foi o primeiro instrumento para a certificação do engajamento comunitário/cívico de instituições de ensino superior. O community engagement diz respeito "a colaboração entre instituições de educação superior e suas comunidades (local, regional/estadual, nacional, global) para o intercâmbio mutuamente benéfico de conhecimentos e recursos, em um contexto de parceria e reciprocidade" (CARNEGIE FOUNDATION..., 2018, p. 1). As instituições interessadas em receber ou manter a certificação na dimensão "curricular engagement" devem explicitar se o engajamento está inserido nas estruturas curriculares.

Na Universidade de Wisconsin, o Morgridge Center for Public Service, por exemplo, oferece diversas disciplinas com community-based learning. As aulas de aprendizagem com base na comunidade comumente incluem pelo menos 25 horas de serviço ao longo do semestre como parte do requisito para a conquista dos créditos (UNIVERSITY OF WISCONSIN-MADSON, 2019).

No continente europeu, por exemplo, a União Europeia lançou em 2013 o “Europe Engage” com o objetivo de promover uma agenda para o engajamento cívico no ensino superior, inclusive com recomendações para a sua inserção curricular, a partir do seguinte entendimento: 
aprendizagem de serviço [...] é uma abordagem pedagógica inovadora que integra serviço ou envolvimento significativo da comunidade no currículo e oferece crédito acadêmico aos alunos pela aprendizagem derivada do envolvimento ativo na comunidade e trabalhe em um problema do mundo real. Reflexão e estratégias de aprendizagem experimental sustentam o processo e o serviço está vinculado à disciplina (MCILRATH et al., 2016, p. 5 apud GRÖNLUND et al., 2017, p. 5).

Na Universidade de Manchester (Inglaterra), o University College for Interdisciplinary Learning oferece aos estudantes diversas possibilidades de conquistar créditos curriculares em disciplinas que combinam conhecimentos teóricos com atividades práticas. Um exemplo disso, é o Manchester Leadership Programme, no qual o estudante deve cumprir créditos em disciplinas além de horas de voluntariado, ou ainda, o Enterprise Challenge, que combina créditos em disciplinas com horas de trabalho comunitário (UNIVERSITY OF MANCHESTER, 2019).

Nos países de língua espanhola os termos mais comumente utilizados são "aprendizaje-servicio" e "aprendizaje experiencial" ou ainda, "educación experiencial”. Camilloni (2013, p. 17) explica que a educação experiencial é "uma estratégia de ensino na qual os alunos aplicam suas habilidades e conhecimentos acadêmicos e profissionais específicos para atender às reais necessidades sociais".

Menéndez e Tarabella (2017) relatam o esforço da Universidad Nacional del Litoral para realizar a integração curricular da aprendizagem experiencial nos cursos de graduação. Segundo os autores, desde o ano de 2007 vêm sendo realizadas ações nesse sentido, sendo que o primeiro passo foi a criação da "Área de Incorporação Curricular da Extensão", junto à Secretaria de Extensão da universidade. Em 2014, foi elaborado o “Documento General de Prácticas de Extensión en Educación Experiencial”, para servir de guia à estruturação de projetos de educação experiencial e para pensar as formas como "a Universidade pode contribuir para o desenvolvimento local e/ou regional, considerando as políticas públicas vigentes, os critérios para incorporação curricular e os modos de avaliação da aprendizagem” (MENÉNDEZ; TARABELLA, 2017, p. 102).

Segundo o Manual Iberoamericano de Indicadores de Vinculación de la Universidad con el Entorno Socioeconómico, as diferentes concepções de extensão e de vinculação das universidades com o seu entorno dificultam a criação de um conceito único, o que se reflete também, nas atividades de mensuração. Além disso, o Manual também considera que "uma das principais dificuldades que surgem com o alinhamento curricular é a capacidade de estabelecer objetivamente o grau em que a comunidade não acadêmica influencia o perfil dos programas de estudo" (OCTS-OEI; RICYT, 2017, p. 30).

\subsection{Breve histórico da extensão no Brasil: das primeiras experiências à curricularização}

No Brasil, as primeiras experiências com a extensão universitária surgiram entre os anos de 1911 e 1917, a partir de cursos e palestras (NOGUEIRA, 2001), embora não houvesse um alinhamento dessas 
ações com questões econômicas e sociais ou com demandas da comunidade (CARBONARI; FERREIRA, 2007). Também não existia a obrigatoriedade de um vínculo estreito (indissociabilidade) entre ensino, pesquisa e extensão, como atualmente. A partir dos anos 1920 surge a extensão rural, nas Escolas Superiores de Lavras (1921) e de Viçosa (1929), inspirada no modelo de extensionista dos Estados Unidos, para prestação de assistência técnica aos agricultores (ROCHA, 2001).

A primeira referência legal à extensão universitária somente ocorreu com o advento do Estatuto das Universidades Brasileiras (Decreto n 19.851, de 11 de abril de 1931), que estabeleceu que a extensão se realizaria por meio de cursos e conferências, mas o processo de institucionalização da extensão somente iniciou nos anos 1960, a partir da Lei de Diretrizes e Bases da Educação (Lei n 4.024, de 20 de dezembro de 1961). Outro marco importante ocorreu no ano de 1987, com a criação do Fórum de Pró-Reitores de Extensão das Instituições Públicas de Educação Superior Brasileiras (Forproex), quando foram estabelecidos os benefícios da extensão universitária para o ensino:

\begin{abstract}
A extensão é uma via de mão-dupla, com trânsito assegurado à comunidade acadêmica, que encontrará, na sociedade, a oportunidade da elaboração da práxis de um conhecimento acadêmico. No retorno à universidade, docentes e discentes trarão um aprendizado que, submetido à reflexão teórica, será acrescido àquele conhecimento. Este fluxo, que estabelece a troca de saberes sistematizados/acadêmico e popular, terá como consequência: a produção de conhecimento resultante do confronto com a realidade brasileira e regional; e a democratização do conhecimento acadêmico e a participação efetiva da comunidade na atuação da universidade. Além de instrumentalizadora deste processo dialético de teoria/prática, a extensão é um trabalho interdisciplinar que favorece a visão integrada do social (FORPROEX, 1987, p. 11).
\end{abstract}

Com a Constituição Federal de 1988, ensino, pesquisa e extensão passaram a ser considerados indissociáveis, mas foi somente com a Lei no 10.172/2001, que institui o segundo Plano Nacional de Educação - PNE, que a curricularização tornou-se obrigatória para as IES federais. O terceiro PNE (Lei n ${ }^{\circ}$ 13.005/2014) tornou essa exigência obrigatória para todas as IES. Mais recentemente, uma Resolução do Ministério da Educação (nº 7/2018), estabeleceu as diretrizes para a inserção da extensão nas matrizes curriculares dos cursos de graduação (BRASIL, 2018). Essa resolução será tratada na seção a seguir.

\title{
3.3 Diretrizes para a curricularização da extensão nas IES brasileiras
}

Embora prevista desde 2001, a curricularização da extensão universitária somente foi regulamentada em 2018. Isso ocorreu por intermédio da Resolução CNE/CES n 7 (em dezembro de 2018), que estabeleceu as diretrizes para as práticas de extensão nas IES brasileiras e regimentou disposições presentes na Meta 12.7, do Plano Nacional de Educação (PNE 2014-2024). Em vista dessas normas, $10 \%$ da carga horária total dos cursos de graduação deverá ser composta por atividades de extensão (artigo $4^{\circ}$ ). O conceito de extensão está expresso no artigo $3^{\circ}$ da Resolução, segundo o qual:

Art. $3^{\circ}$ A Extensão na Educação Superior Brasileira é a atividade que se integra à matriz curricular e à organização da pesquisa, constituindo-se em processo interdisciplinar, político educacional, 
cultural, científico, tecnológico, que promove a interação transformadora entre as instituições de ensino superior e os outros setores da sociedade, por meio da produção e da aplicação do conhecimento, em articulação permanente com o ensino e a pesquisa (BRASIL, 2018, p. 1-2, grifo nosso).

Conforme estabelece o artigo $7^{\circ}$, somente serão consideradas como extensão as ações que envolvam diretamente "comunidades externas às instituições de ensino superior e que estejam vinculadas à formação do estudante" (BRASIL, 2018, p. 2). Sendo no artigo $8^{\circ}$ definidas as modalidades de ações de extensão: (i) programas; (ii) projetos; (iii) cursos e oficinas; (iv) eventos; e (v) prestação de serviços. A Resolução praticamente reproduziu a caracterização do Forproex (2007), tendo acrescentado apenas o termo "oficinas".

Segundo a resolução, as IES devem proceder a autoavaliação crítica da extensão, identificando a pertinência das ações nas matrizes curriculares, a contribuição da extensão aos objetivos estabelecidos no Plano de Desenvolvimento Institucional (PDI) e nos Projetos Pedagógicos (PPs) dos cursos e explicitar quais são os procedimentos e indicadores utilizados para tal fim (artigos 10 e 11) (BRASIL, 2018, p. 2). A avaliação externa in loco, tanto institucional, quanto dos cursos, ficará sob a responsabilidade do Instituto Anísio Teixeira (INEP), órgão vinculado ao Ministério da Educação (MEC) (art. 12) e das Secretarias Estaduais de Educação, no caso das IES estaduais.

As IES deverão incluir em seus PDI informações referentes as ações de IEE, entre elas: a concepção de extensão, em consonância com a Resolução; as formas de sistematização e de registo das atividades de extensão, desde a formulação das propostas, seu desenvolvimento e conclusão; as estratégias e os procedimentos para a IEE e a forma de participação dos estudantes; formas e estratégias de financiamento da extensão, entre outros (arts. 13 a 16). A Resolução também estabeleceu que poderão ser realizadas parcerias entre IES com fins de estimular a mobilidade interinstitucional de estudantes e docentes (art. 17), além de prever as formas de participação do quadro técnico-administrativo nas atividades de extensão, seu registro e valorização (art. 18). As IES deverão implementar a curricularização em até 3 anos, contados da sua homologação, o que deverá ocorrer até 18 de dezembro de 2021 (art. 19).

\subsection{Estado atual da curricularização nas Instituições Públicas de Ensino Superior brasileiras}

Entre dezembro de 2018 e maio de 2019, o Forproex realizou dois mapeamentos para identificar o estado atual da inserção da extensão universitária nos currículos dos cursos de graduação das Instituições Públicas de Educação Superior (IPES). A seguir, apresentamos uma síntese dos resultados obtidos no segundo mapeamento, que foi realizado entre os dias e 27 de maio de 2019 por meio de questionário online com os responsáveis pelas Pró-Reitorias de Extensão. Os questionários tinham o objetivo de ampliar a compreensão acerca dos cenários investigados na pesquisa anterior. A diferença é que esta rodada continha questões qualitativas, nas quais podia-se incluir justificativas para as respostas. 
Responderam à esta segunda pesquisa 68 (48,2\%) das 141 IPES (67 - 47,5\% com respostas válidas e 1 inválida). Os resultados apurados foram os seguintes:

- Em 42 IPES (62,7\%) a escolha do modelo de proposta ou de normativa interna ainda estava em andamento: desde consultas gerais à comunidade acadêmica, para esclarecimento do tema, até discussões mais estruturadas no âmbito das comissões de extensão, ou ainda, a minuta do instrumento normativo já havia sido encaminhada para votação nas instâncias superiores (Conselho ou similar).

- Em 56,33\% das instituições o processo encontrava-se em fase inicial, ou seja, em debates sobre o modelo de inserção da extensão nos currículos, mas não existia uma minuta ou pauta do instrumento normativo. Em $21,12 \%$ das instituições, no entanto, já existia uma minuta de resolução em elaboração.

- Em 18 instituições (26,7\%) já existia uma normativa aprovada e publicada e a curricularização já estava em andamento (inserção na matriz curricular e ajustamento dos projetos pedagógicos). Em alguns casos, os PP dos cursos já haviam sido reformulados, além de já serem oferecidas unidades curriculares da Extensão, em alguns cursos de graduação (em apenas 2 instituições).

- Apenas 1 instituição declarou já ter concluído o processo integralmente com normativa publicada, todos os PPC reformulados e 100\% dos cursos oferecendo extensão. Entretanto, ao analisar as respostas dadas às questões subsequentes, o Forproex concluiu, que, na verdade, somente $88,16 \%$ dos cursos, realmente, ofereciam unidades curriculares de Extensão. Isso foi depreendido do próprio relato da instituição, que revelou existir ainda certa dificuldade, da parte dos docentes, para trabalharem com as dimensões "interprofissional" e "interdisciplinar" para possibilitar "maior liberdade e protagonismo ao estudante na escolha de seu processo formativo"”. Além disso, também ocorreram conflitos de "carga horária", o que ocasionou a realização de discussões mais demoradas para a revisão curricular.

- Em 6 instituições (9\%) ainda não havia sido iniciado o debate sobre o tema devido, por exemplo, às dificuldades de articulação e convencimento da comunidade acadêmica (COIMBRA et al., 2019).

Em termos gerais, os resultados do mapeamento permitiram concluir que, embora grande parte das IPES já tivesse iniciado o processo antes da Resolução CNE/MEC (2018), muitas instituições imprimiram maior celeridade ao processo. Como resultado, o número de instituições que ainda não tinha iniciado o processo, caiu de 10 (dezembro de 2018) para 6 (maio de 2019) (COIMBRA et al., 2019).

\section{Como avaliar a integração ensino-extensão (IEE)?}

Existem diversas estruturas analíticas (frameworks) para avaliação da relação universidadesociedade, algumas focadas na vinculação com o entorno e comunidade (community engagement), impacto social da universidade, relação ensino e extensão (service-learning), por exemplo. Neste artigo, entretanto, focamos especificamente em sistemas e indicadores de avaliação da integração ensinoextensão. 
Segundo Hollander, Saltmarsh e Zlotkowski (2002), ao estudarem as iniciativas de diversos campi participantes da iniciativa Campus Compact buscaram entender as atividades, políticas e a estrutura institucionais. A partir daí, afirmam que dois tipos de autoavaliação do engajamento podem ser realizados em combinação: 1) inventário das ações de engajamento; 2) qualidade e relevância das ações realizadas. Para essas avaliações, os autores chegaram ao total de dez indicadores para os quais definiram exemplos de perguntas-chave, métricas e iniciativas relacionadas. Diversos desses indicadores influenciam a integração ensino-extensão, porém, agem mais diretamente sobre ensino e pedagogia, sendo eles: número de disciplinas com IEE/ano, proporção dos docentes envolvidos, presença de metas no planejamento estratégico institucional, número de estudantes envolvidos, distribuição das disciplinas por área do conhecimento etc.

Uma avaliação mais geral sobre engajamento vem da certificação Carnegie Elective Community Engagement Classification que divide os indicadores em quatro dimensões: missão cívica, parcerias, epistemológica (geração e apropriação do conhecimento) e pedagógica (onde se encaixa a IEE). No caso da IEE, essa é avaliada pela integração no currículo e nas atividades extracurriculares e seus respectivos indicadores que são: ensino e aprendizado, currículo; atividades extracurriculares; apoio e valorização (CARNEGIE FOUNDATION..., 2018).

Waters e Anderson-Lain (2014) fazem uma distinção importante de formas de se avaliar o aprendizado em serviço: a avaliação qualitativa (formativa) realizada durante as ações de IEE com o intuito de entender o uso de recursos e o aprendizado; e a avaliação quantitativa (summative) que ocorre ao final de um período de interesse (final da disciplina, do ano letivo, etc.). Entende-se que a avaliação formativa é uma importante distinção entre as atividades de IEE e as atividades extracurriculares e essencial ao aprendizado.

Gelmon, Holland e Spring (2018), a partir de um trabalho de Driscoll et al. (1996) publicaram um guia para avaliação institucional da IEE no qual propõem um processo em três partes:

- Determinação do formato da avaliação: definir o objetivo e motivações da avaliação, público interessado na avaliação, recursos disponíveis, responsáveis pela condução da análise, período de avaliação, e forma de uso das análises. Como interessados, pode-se ter: órgãos regulatórios ou governamentais, docentes e estudantes. No caso do uso da análise pode-se ter planejamento de novas estratégias e formas de engajamento e IEE, análise dos resultados e impactos da IEE de outras instituições, fomento para contratação docente, entre outros.

- Determinação dos envolvidos na análise: envolver diferentes atores, com diferentes escopos (programas, disciplinas, ação de extensão etc.), interesses, e experiências, tais como, estudantes, docentes, parceiros da comunidade, liderança institucional etc. Além disso, qual o papel de cada um no processo.

- Seleção do método de avaliação: métodos quali e/ou quantitativos de análise, nível de generalização, validade dos resultados, técnicas de coleta e análise, tipos de dados etc. 
- Avaliação multistakeholder do impacto da IEE: para os estudantes; docentes; comunidade; e a instituição de ensino superior.

Gelmon, Holland e Spring (2018) fornecem uma matriz de avaliação, estratégias e exemplos de instrumentos. Entre os instrumentos estão: levantamentos com estudantes e parceiros, grupos focais, observação durante as atividades, relatórios etc. A matriz baseia-se em quatro perguntas: O que queremos saber? O que estamos buscando? O que mediremos? Como levantaremos evidências sobre o que gostaríamos de saber? No Quadro 1 apresentamos uma adaptação da matriz acrescentando a coluna dimensão e reduzindo o número de conceitos-chave, já que os autores criaram uma matriz para cada dimensão da avaliação.

Furco (1999, 2006), por sua vez, criou uma matriz para se avaliar a relevância das ações de IEE que se baseia em cinco categorias e três estágios de comprometimento. Os estágios são: 1) construção de massa crítica; 2) construção da qualidade; 3) institucionalização sustentada. As categorias gerais e critérios relacionados a IEE são descritos no Quadro 2.

Quadro 1 - Matriz de avaliação da integração ensino e extensão: exemplos

\begin{tabular}{|c|c|c|c|c|}
\hline Dimensão & Conceitos-chave & Indicadores -chave & Método de coleta & Fonte dos dados \\
\hline Estudantes & $\begin{array}{l}\text { consciência da } \\
\text { comunidade }\end{array}$ & $\begin{array}{l}\text { conhecimento dos desafios da } \\
\text { comunidade; entendimento } \\
\text { das forças, problemas e } \\
\text { recursos da comunidade }\end{array}$ & $\begin{array}{c}\text { Entrevistas; grupos } \\
\text { focais; observações em } \\
\text { sala }\end{array}$ & $\begin{array}{l}\text { estudantes; } \\
\text { docentes; } \\
\text { parceiros }\end{array}$ \\
\hline $\begin{array}{l}\text { Comunidad } \\
\text { e }\end{array}$ & satisfação com a parceria & $\begin{array}{l}\text { percepção de reciprocidade; } \\
\text { capacidade de resposta aos } \\
\text { desafios }\end{array}$ & $\begin{array}{c}\text { entrevistas } \\
\text { análise documental } \\
\text { método de incidentes } \\
\text { críticos }\end{array}$ & $\begin{array}{l}\text { parceiros; } \\
\text { docentes; } \\
\text { conselho de } \\
\text { administração }\end{array}$ \\
\hline Docente & métodos de ensino & $\begin{array}{l}\text { influência da IEE na aula; } \\
\text { organização e interações em } \\
\text { sala de aula }\end{array}$ & $\begin{array}{c}\text { observações em sala; } \\
\text { diários; } \\
\text { levantamentos }\end{array}$ & $\begin{array}{l}\text { estudantes; } \\
\text { docentes }\end{array}$ \\
\hline Institucional & papel na comunidade & $\begin{array}{l}\text { número e tipos de solicitações } \\
\text { da comunidade; } \\
\text { mudanças na procura pelos } \\
\text { cursos }\end{array}$ & $\begin{array}{l}\text { entrevistas; } \\
\text { relatórios institucionais }\end{array}$ & $\begin{array}{l}\text { conselho de } \\
\text { administração; } \\
\text { repositórios } \\
\text { institucionais }\end{array}$ \\
\hline
\end{tabular}

Fonte: Adaptado de Driscoll et al. (1996) e Gelmon, Holland e Spring (2018). 
Quadro 2 - Sistema de avaliação da interação ensino e extensão

\begin{tabular}{|c|c|c|}
\hline Categorias da análise do engajamento & Categorias focadas em IEE & Perspectiva \\
\hline $\begin{array}{l}\text { I. Filosofia e missão da IEE } \\
\text { II. Apoio e envolvimento do docente na } \\
\text { IEE } \\
\text { III. Apoio e envolvimento do aluno na } \\
\text { IEE } \\
\text { IV. Participação da comunidade e } \\
\text { parcerias } \\
\text { V. Apoio institucional }\end{array}$ & $\begin{array}{l}\text { - Definição de IEE } \\
\text { - Planejamento estratégico } \\
\text { - Alinhamento com a missão institucional } \\
\text { - Alinhamento com esforços de mudanças educacionais } \\
\text { - Percepção dos docentes, alunos e parceiros } \\
\text { - Envolvimento e apoio aos docentes } \\
\text { - Liderança do corpo docente e do aluno } \\
\text { - Incentivos e recompensas do corpo docente e do aluno } \\
\text { - Oportunidades para o aluno } \\
\text { - Compreensão mútua } \\
\text { - Liderança e voz da agência comunitária }\end{array}$ & Institucional - IEE \\
\hline
\end{tabular}

Fonte: elaboração própria com base em Furco (1999, 2006).

Nessa mesma linha, a Kellogg Comission... (1999) criou um teste de sete dimensões para determinação da relevância do engajamento com a comunidade, sendo elas: capacidade de resposta (ouvir a comunidade); respeito a habilidades e capacidades dos parceiros; neutralidade da universidade; igualdade de acessibilidade pelos parceiros; integração entre a missão da universidade e o engajamento; compartilhamento de conhecimento em formato claro a todos; adequação dos recursos mobilizados.

No estudo "A Framework for Community Engaged Scholarship" foram estabelecidos diversos critérios para avaliação do engajamento das universidades com as comunidades a partir de três dimensões ou esferas do trabalho docente: ensino, pesquisa e serviço. Com base nos trabalhos de Glassick, Huber e Maeroff (1997), a instituição sugere sete critérios de avaliação: clareza das metas de engajamento do docente; preparação adequada; métodos adequados para atingir as metas; relevância dos resultados alcançados; apresentação efetiva dos resultados; reflexão crítica de sua atuação (CONNECTICUT CAMPUS COMPACT, 2012).

No caso da atuação docente no ensino engajado com a comunidade, o Engaged Scholarship Advisory Committee do Connecticut Campus Compact (2012) sugere um processo de dois passos: 1) adoção da aprendizagem em serviço para melhorar o ensino docente e o aprendizado do estudante; 2) compartilhamento público de ideias sobre o impacto da ação na comunidade, estudantes e no aperfeiçoamento do ensino do docente. Também são sugeridos como critério de avaliação, o sucesso da IEE na perspectiva do aluno, considerando as questões como: os alunos aprendem a aplicar teoria e métodos práticos em situações concretas? Os alunos são incentivados a apreciar as suas capacidades de intervir no mundo e dos outros também o fazerem? Os alunos são reconhecidos pela qualidade do seu trabalho por outras pessoas que não o instrutor, incluindo outros alunos e parceiros da comunidade? A experiência de ensino é documentada e disseminada?

Camilloni (2017) propõe um método de avaliação de projetos de extensão ligados ao ensino a partir da consideração do contexto no qual os projetos acontecem e dos objetivos da IEE. O método é 
composto pelos critérios: avaliação da atividade docente, avaliação da qualidade dos produtos/serviços prestados, a avaliação da relação da universidade com a comunidade e a institucionalização da extensão na universidade.

No caso brasileiro, constamos que existem poucos estudos focados na integração IEE. Nos Indicadores Brasileiros de Extensão Universitária (IBEU), Maximiliano Junior (2017) coloca alguns critérios e métricas de avaliação, que alteramos para incluir na proposta apresentada na seção 5.

\section{Proposta de um sistema de avaliação da integração ensino e extensão}

Nesta seção propomos um sistema de avaliação da integração ensino-extensão (curricularização) para universidades públicas brasileiras, a partir dos seguintes passos:

- Determinação do objetivo da avaliação: seja para cumprir requisitos legais ou para avaliar e aperfeiçoar as práticas e impactos da IEE.

- Determinação do formato da avaliação e sua periodicidade: autoavaliação ou avaliação por entidade externa, por unidades de ensino ou visão geral. Influem na tomada de decisão os interessados e a disponibilidade de recursos a serem destinados a IEE.

- Determinação dos envolvidos e seus papéis: sugere-se grupo multidisciplinar, multistakeholder.

- Seleção dos métodos de avaliação: tipo de pesquisa e métodos de coleta e análise, além da determinação dos tipos de dados e indicadores utilizados. É importante garantir avaliações formativas e quantitativas conforme descrito na seção anterior. A seguir sugerimos uma lista de critérios e indicadores possíveis.

- Avaliação multistakeholder do impacto da IEE: para os estudantes, docentes, parceiros da comunidade, e para a gestão universitária.

- Comunicação da avaliação: formas de publicação e difusão.

- Sugestão de uso dos dados para aperfeiçoamentos da IEE e do sistema de avaliação: planejamento de novas estratégias de IEE, requisitos para contratação docente, entre outros.

Com base na pesquisa na literatura analisada, especialmente, a partir do trabalho realizado por Maximiliano Junior (2017), bem como em análise documental, sugerimos as seguintes dimensões e indicadores de análise institucional quantitativa (summative) da IEE apresentados no Quadro 3. 


\section{Quadro 3 - Sistema de avaliação da interação ensino e extensão (IEE) (continua)}

\begin{tabular}{|c|c|}
\hline Dimensão & Indicador \\
\hline \multirow{17}{*}{$\begin{array}{c}\text { Situação da } \\
\text { Integração } \\
\text { ensino- } \\
\text { extensão }\end{array}$} & Número de disciplinas com IEE \\
\hline & Treinamentos ministrados na temática de extensão para o púbico interno \\
\hline & Alunos bolsistas em extensão \\
\hline & Ações de empreendedorismo ligadas à IEE \\
\hline & Oferecimento de disciplinas de graduação ou pós-graduação que discutem a temática da extensão \\
\hline & Eventos sobre a temática de IEE incluindo conceito, sistematização, avaliação e indicadores, e outros. \\
\hline & Projetos de pesquisa, incluindo iniciação científica, sobre IEE \\
\hline & Monografias orientadas em extensão, tais como dissertações e teses. \\
\hline & Inserção da extensão em trabalhos de final de curso, dissertações e teses \\
\hline & Proporção dos cursos com $10 \%$ da carga horária integrada com extensão \\
\hline & Alinhamento das ações de IEE com as diretrizes do Forproex \\
\hline & Programas e projetos de extensão envolvidos na IEE \\
\hline & Colaboração entre unidades da universidade e entre outras universidades para IEE \\
\hline & Ações interdisciplinares de IEE \\
\hline & Parceiros públicos, privados e segmentos organizados das ações de IEE \\
\hline & Participação e envolvimento de docentes nas ações de IEE \\
\hline & Eventos sobre IEE realizados \\
\hline Dimensão & Indicador \\
\hline \multirow{3}{*}{$\begin{array}{c}\text { Situação da } \\
\text { Integração } \\
\text { ensino- } \\
\text { extensão }\end{array}$} & Estratégias de integração utilizadas \\
\hline & Ações de apoio, aperfeiçoam e fortalecimento \\
\hline & Barreiras e desafios encontrados \\
\hline \multirow{10}{*}{$\begin{array}{c}\text { Contribuição } \\
\text { para a } \\
\text { universidade }\end{array}$} & Contribuições geradas a partir da IEE, tais como novas linhas de pesquisa, mudanças curriculares, novas metodologias etc. \\
\hline & Produção de materiais e métodos para instrumentalização da IEE \\
\hline & Produção de livros ou capítulos com base em resultados da IEE \\
\hline & Publicação de artigos em periódicos com base em resultados da IEE \\
\hline & Comunicações em eventos com base em resultados da IEE \\
\hline & Produções áudios-visuais geradas a partir de resultados da IEE \\
\hline & Relevância das ações de IEE para a universidade \\
\hline & Produção acadêmica sobre IEE, tais como livros, artigos científicos, relatórios técnicos, patentes etc. \\
\hline & Os tipos de ações de integração praticadas são consistentes com as diretrizes e objetivos estratégicos da universidade? \\
\hline & Inovações para e a partir da integração \\
\hline \multirow{9}{*}{$\begin{array}{c}\text { Contribuiçãa } \\
\text { para a } \\
\text { sociedade }\end{array}$} & Nível de colaboração de outras instituições e não acadêmicos nas ações de IEE \\
\hline & Público alcançado pelas ações de IEE \\
\hline & Ações de IEE dirigidas às escolas públicas e outras organizações da sociedade civil \\
\hline & Inclusão de população vulnerável nas ações de IEE \\
\hline & Municípios atendidos por ações de IEE \\
\hline & Número de produções científicas, artísticas e esportivas produzidas a partir da IEE \\
\hline & Tipo de envolvimento da comunidade \\
\hline & Relevância das ações de IEE junto à comunidade externa \\
\hline & Relevância das ações de extensão do ponto de vista social, econômico e político para o país, a comunidade regional e local. \\
\hline \multirow{3}{*}{$\begin{array}{c}\text { Contribuição } \\
\text { para o aluno } \\
\text { participante }\end{array}$} & Papel dos estudantes nas ações de extensão \\
\hline & Acesso dos alunos a diversidade de ações \\
\hline & Aprendizagem técnica do aluno \\
\hline
\end{tabular}

Avaliação, Campinas; Sorocaba, SP, v. 25, n. 02, p. 395-415, jul. 2020 


\begin{tabular}{|c|c|}
\hline \multirow{4}{*}{ 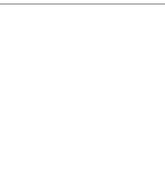 } & Iniciativa do aluno \\
\hline & Relacionamento pessoal e interação social \\
\hline & Capacidade do aluno de propor soluções e trabalhar com problemas sociais \\
\hline & Participação em atividades extracurriculares \\
\hline \multirow{3}{*}{$\begin{array}{l}\text { Apoio e } \\
\text { Valorização }\end{array}$} & Estímulo para que os estudantes realizem atividades de extensão, culturais, artísticas e esportivas para a comunidade \\
\hline & Adequação de infraestrutura, como salas de aula, espaço para estudo em grupo, outros. \\
\hline & $\begin{array}{l}\text { Procedimentos institucionalizados para planejamento, aprovação, acompanhamento, financiamento e avaliação das ações de } \\
\text { integração }\end{array}$ \\
\hline
\end{tabular}

Fonte: elaboração própria com base na pesquisa bibliográfica e documental.

Sustentamos também a necessidade de se pensar em formas de avaliação e integração que considerem as ações que já são desenvolvidas pelos estudantes e constituem mecanismos de atuação já consolidados, como é o caso da atuação em empresas juniores e congêneres, como uma forma de reconhecimento e valorização do protagonismo estudantil. Segundo o Forproex (2007), uma das formas de operacionalização da "linha de extensão" - "empreendedorismo", é por meio da constituição e gestão de empresas juniores, incubação, cooperativismo, empreendimentos solidários, entre outros.

Recomendamos que sejam criados mecanismos de certificação dessas atuações, oferecendo ao estudante a possibilidade de conquistar os créditos curriculares da extensão. Nessa mesma categoria poderiam ser englobadas iniciativas voltadas à geração de empreendedorismo social (ex. Enactus). Cabe lembrar que ambos os movimentos valorizam e estimulam o protagonismo do estudante, envolvem demandas da sociedade, bem como requerem conhecimentos conquistados no âmbito das disciplinas e do curso. Entretanto, para serem válidas tais ações necessitam do envolvimento docente para a consolidação do aprendizado ocorrido nas ações extracurriculares. Dessa forma, um trabalho colaborativo entre alunos e docentes é fundamental para os resultados da IEE.

A população a ser investigada engloba estudantes e docentes das IES, parceiros, comunidades e indivíduos beneficiados pela IEE, gestores, que constituem também fontes de dados primários. Como fontes de dados secundários podem ser considerados: planos estratégicos, declarações de identidade institucional (missão, por exemplo), relatórios institucionais, programas e planos de disciplinas etc.

Como métodos de coleta de dados sugerimos entrevistas com estudantes, docentes e parceiros, realização de grupos focais com estudantes e membros da comunidade, análise de documentos institucionais e de projetos de IEE, observações em sala de aula (e nas ações de extensão), diários de pesquisa de campo e diários pessoais, levantamentos com diversos atores, entre outros.

\section{Considerações finais}

Neste artigo propomos um sistema de avaliação da curricularização da extensão para universidades públicas brasileiras, tendo como ponto de partida as diretrizes da extensão estabelecidas pelo 
Forproex (2012), a Política Nacional de Extensão Universitária e a Resolução CNE/CES nº 7/2018 que compartilham as mesmas diretrizes de extensão universitária: interação dialógica entre conhecimentos; interdisciplinaridade e interprofissionalidade; indissociabilidade entre ensino-extensão-extensão; formação humana e profissional do discente; e o impacto na sociedade.

Reflexões e análises, embasadas em amplo levantamento bibliográfico e documental, permitiram que estabelecêssemos os passos a serem observados para a criação de um sistema de avaliação da integração ensino-extensão, suas dimensões de análise e seus respectivos indicadores. Conforme apresentado na seção 4, o processo de avaliação sugerido envolve sete passos que vão do planejamento até a comunicação e uso das informações, sendo que as dimensões envolvem os seguintes critérios: situação da integração ensino-extensão, contribuição para a universidade, contribuição para a sociedade, contribuição para o aluno participante; e apoio e valorização.

Nota-se também, a importância do trabalho do Forproex, produzindo conhecimento, conceituando e elaborando documentos orientadores à prática da extensão no país, estabelecendo as bases para o atual marco legal da extensão universitária.

A pesquisa também permitiu constatar que as principais estratégias adotadas para a implantação da curricularização nas IES brasileiras, comumente envolvem a criação de disciplinas específicas de extensão (novas disciplinas), criação ou reconhecimento de créditos curriculares em disciplinas já existentes, creditação de atividades de extensão realizadas fora da unidade de ensino do aluno, trabalhos de conclusão de curso a partir de problemas levantados com a comunidade local etc.

Outra constatação é a importância da comunicação e integração entre diferentes atores como membros da comunidade, alunos, docentes e gestores universitários a fim de uma melhor integração extensão e ensino. Bem como a importância de se comunicar e utilizar os resultados da avaliação.

É importante ressaltar que a existência de um sistema de avaliação é imprescindível, tanto em cumprimento das determinações legais quanto para acompanhamento e melhoria da IEE pela própria instituição. Cabe lembrar que, conforme constatou o Forproex, a partir de mapeamentos, em algumas IES a comunidade acadêmica tem oferecido resistência, o que tem obstaculizado o andamento das discussões e tornado mais moroso o processo de inserção curricular da extensão. Logo, é importante destacar que nenhuma lei tem o condão de convencimento e de adesão voluntária, e mais importante, a extensão não deve ser vista como uma mera obrigação legal e sim como uma estratégia institucional de aperfeiçoamento de seu ensino, pesquisa e extensão, bem como de sua atuação nas demandas e desafios sociais.

Nota-se, portanto, que é necessário ainda superar dificuldades, desmitificar, elucidar e ampliar a compreensão da extensão universitária como uma missão tão importante quanto o ensino e a pesquisa, para que tenha o reconhecimento e a valorização que merece. Frente a tantos desafios enfrentados pelas 
universidades brasileiras, principalmente as públicas, é importante e urgente a criação, valorização e intensificação de uma cultura de parceria com outros membros da sociedade.

Assim, um sistema de avaliação da IEE é essencial não apenas para o sucesso da implementação de ações, mas também para que as experiências positivas e negativas possam ser mapeadas, discutidas e divulgadas, inclusive para a atualização do próprio quadro regulatório, da gestão institucional e da cultura das instituições envolvidas.

Como nosso trabalho não teve como objetivo aplicar o sistema de avaliação sugerido, trabalhos futuros podem explorar a implantação do sistema de avaliação aqui sugerido, bem como estudar seus pontos fortes e falhas, além de seus impactos para os diferentes atores e instituições.

\section{Agradecimentos}

Agradecemos à Pró-reitoria de Extensão e Cultura da Universidade Estadual de Campinas pelo apoio a esta pesquisa e à CAPES (Processo no 88887.176105/2018-00 - INCT-PPED) pelo apoio via bolsa de pós-doutorado.

\section{Referências}

ANGELES, Consideraciones en torno al concepto de extensión de la cultura y de los servicios. Revista de la Educación Superior, Ciudad de México, n. 81, v. 21, n. 1, p. 1-9, 1992. Disponível em: http://publicaciones.anuies.mx/revista/81. Acesso em: 13 mar. 2020.

BERNASCONI, Andrés. Is there a Latin American model of the university? Comparative education review, Boston, v. 52, n. 1, p. 27-52, 2008. Disponível em: https://ejournals.bc.edu/index.php/ihe/article/view/8031. Acesso em: 13 mar. 2020.

BRASIL. Ministério da Educação. Resolução n 7, de 18 de dezembro de 2018. Disponível em: http://portal.mec.gov.br/index.php?option=com_docman\&view=download\&alias=104251-rces00718\&category_slug=dezembro-2018-pdf\&Itemid=30192. Acesso em: 10 set. 2019.

CAMILLONI, Alicia R. W. de. La inclusión de la educación experiencial en el currículo universitario. In: MENÉNDEZ, G. et al. Integración docencia y extensión. Otra forma de enseñar y de aprender. Santa Fe: Universidad Nacional del Litoral, 2013. p. 11-21. Disponível em: http://biblioteca.clacso.edu.ar/Argentina/fcjs-un1/20171101043348/pdf_1172.pdf. Acesso em: 20 ago. 2019.

CAMILLONI, Alicia R. W. de. La evaluación en proyectos de extensión incluidos en el currículo universitario. +E: Revista de Extensión Universitaria, Santa Fe, v. 6, n. 6, p. 24-35, 8 mar. 2017. Disponível em: https://bibliotecavirtual.unl.edu.ar/publicaciones/index.php/Extension/article/view/6310. Acesso em: 10 set. 2019.

CARBONARI, Maria Elisa Ehrhardt; FEREIRA, Adriana Camargo. A extensão universitária no Brasil, 
do assistencialismo à sustentabilidade. Revista de Educação, Itatiba, v. 10, n. 10, p. 23-28, 2007.

Disponível em:

http://www.consultaesic.cgu.gov.br/busca/dados/Lists/Pedido/Attachments/555968/RESPOSTA_REC

URSO_1_A\%20extenso\%20universitria\%20no\%20Brasil.pdf. Acesso em: 10 jun. 2019.

CARNEGIE FOUNDATION FOR THE ADVANCEMENT OF TEACHING. Carnegie

Community Engagement Classification 2020. 2018. Disponível em:

https://www.brown.edu/swearer/carnegie/2020-classification-application-information. Acesso em: 01 set. 2019.

COIMBRA, Ana Lívia de Souza et al. Mapeamento da inserção da extensão nos currículos dos cursos de graduação das instituições públicas de educação superior brasileira. In: FORPROEX. Relatório Final da Coordenação Nacional. Belo Horizonte: UFMG, 2019. Disponível em: https://www.ufmg.br/proex/renex/images/RELAT\%C3\%93RIO_FINAL_MAPEAMENTO_INSERC AO_EXTENSAO_FINAL.pdf. Acesso em: 15 set. 2019.

CONNECTICUT CAMPUS COMPACT. A Framework for Community Engaged Scholarship. 2012. Disponível em: https://compact.org/resource-posts/a-framework-for-community-engagedscholarship/. Acesso em: 14_set. 2019.

CONWAY, Cheryl et al. Characterising modes of university engagement with wider society: a literature review and survey of best practice. (Final Report). Newcastle upon Tyne: Newcastle University, 2009. Disponível em: https://strathprints.strath.ac.uk/48210/. Acesso em: 13 mar. 2020.

COOPER, Donald R.; SCHINDLER, Pamela. Business research methods. New York: McGrawHill//rwin, 2010.

DRISCOLL, Amy et al. An Assessment Model for Service-Learning: comprehensive case studies of impact on faculty, students, community, and institution. Michigan Journal of Community Service Learning, Ann Arbor, v. 3, n. 1, p. 66-71, 1996. Disponível em:

http://hdl.handle.net/2027/spo.3239521.0003.107. Acesso em: 20 ago. 2019.

FORPROEX - ENCONTRO DE PRÓ-REITORES DE EXTENSÃO DAS UNIVERSIDADES PÚBLICAS BRASILEIRAS, 1., 1987, Brasília. Conceito de extensão, institucionalização e financiamento. BRASÍLIA: UNB, 1987. Disponível em:

https://www.ufmg.br/proex/renex/images/documentos/1987-I-Encontro-Nacional-do-FORPROEX.pdf. Acesso em: 10 set. 2019.

FORPROEX. Extensão Universitária: organização e sistematização. Organização: Edison José Corrêa. Coordenação Nacional do FORPROEX. Belo Horizonte: Coopmed, 2007.

FORPROEX. Política Nacional de Extensão Universitária. Manaus: Forproex, 2012. Disponível em: https://proex.ufsc.br/files/2016/04/Pol\%C3\%ADtica-Nacional-de-Extens\%C3\%A3oUniversit\%C3\%A1ria-e-book.pdf. Acesso em: 10 set. 2019.

FREITAS NETO, José Alves de. A reforma universitária de Córdoba (1918): um manifesto por uma universidade latino-americana. Revista Ensino Superior Unicamp, Campinas, v. 3, p. 64-72, 2011. Disponível em: https://www.revistaensinosuperior.gr.unicamp.br/edicoes/ed03_junho2011/11.pdf. Acesso em: 13 mar. 2020. 
FURCO, Andrew. Self-assessment rubric for the institutionalization of service-learning in higher education. Berkeley: Service-Learning Research \& Development Center, University of California, 1999. Disponível em:

https://digitalcommons.unomaha.edu/cgi/viewcontent.cgi?article=1105\&context=slceslgen. Acesso em: 02 set. 2019.

FURCO, Andrew. Self-assessment rubric for the institutionalization of service-learning in higher education (revised 2006). Berkeley: Service-Learning Research \& Development Center, University of California, 2006. Disponível em: https://maaz.ihmc.us/rid=1K3H04ZW0-XXS8LG-ZLZ/furco-rubric2006.pdf. Acesso em: 02 set. 2019.

GLASSICK, Charles E.; HUBER, Mary Taylor; MAEROFF, Gene I. Scholarship Assessed: Evaluation of the Professoriate. Special Report. San Francisco: Jossey-Bass, 1997.

GELMON, Sherril B.; HOLLAND, Barbara A.; SPRING, Amy (eds.). Assessing service-learning and civic engagement: principles and techniques. 2. ed. Boston: Campus Compact, 2018.

GODDARD, John; VALLANCE, Paul. The civic university and the leadership of place. UK: Centre for Urban and Regional Development Studies (CURDS) Newcastle University, 2011. p. 1-22.

Disponível em:

http://citeseerx.ist.psu.edu/viewdoc/download?doi=10.1.1.226.2169\&rep=rep1\&type=pdf. Acesso em: 30 ago. 2019.

GOLDMAN, Lawrence. Dons and Workers: Oxford and Adult Education since 1850. Oxford: Clarendon Press, 1995.

GRÖNLUND, Henrietta et al. Guidelines for Institutionalization of Service-Learning. 2017. Disponível em: https://europeengagedotorg.files.wordpress.com/2015/10/guidelines-euengage-2.pdf. Acesso em: 02 mar. 2020.

HOLLANDER, Elizabeth L.; SALTMARSH, John; ZLOTKOWS, Edward. Indicators of Engagement. In: KENNY, Maureen E. et al. (eds). Learning to serve: promoting civil society through service learning. US: Springer, 2002. v. 7, p. 31-49. Disponível em: https://link.springer.com/content/pdf/10.1007\%2F978-1-4615-0885-4.pdf. Acesso em: 18 mar. 2020.

HOWARD, Jeffrey. Service-Learning Course Design Workbook. Michigan Journal of Community Service Learning, Summer, 2001. Disponível em: https://files.eric.ed.gov/fulltext/ED457774.pdf. Acesso em: 01 ago. 2019.

KELLOGG COMMISSION ON THE FUTURE OF STATE AND LAND-GRANT UNIVERSITIES. Returning to our Roots: the engaged institution. Washington, DC: National Association of State Universities and Land Grant Colleges, 1999. Disponível em: http://www.aplu.org/library/returning-to-our-roots-theengaged-institution/file. Acesso em: 09 jul. 2019.

KERR, Clark. Os usos da universidade. 15. ed. Brasília: UNB, 2005.

LAND-GRANT IMPACTS. About. 2019. Disponível em: https://landgrantimpacts.org/about/. Acesso em: 1 mar. 2020. 
MAXIMILIANO JUNIOR, Manoel (org.). Indicadores Brasileiros de Extensão Universitária (IBEU). Campina Grande, PB: UFCG, 2017.

MENÉNDEZ, Gustavo; TARABELLA, Laura. El aprendizaje experiencial: una práctica de innovación que se afianza en la Universidad Nacional del Litoral. $+\mathbf{E}$ : Revista de Extensión Universitaria, Santa Fe, v. 6, n. 6, p. 96-103, mar. 2017. Disponível em:

https://bibliotecavirtual.unl.edu.ar/publicaciones/index.php/Extension/article/view/6317. Acesso em: 18 mar. 2020.

MCILRATH, Lorraine et al. Europe Engage Survey of Civic Engagement \& Service-Learning Activities within the Partner Universities. Europe Engage Erasmus+project (European Union), 2016. Disponível em:

https://europeengagedotorg.files.wordpress.com/2016/04/report-euen-mcilrath-et-al4.pdf. Acesso em: 18 mar. 2020.

NOGUEIRA, Maria das Dores Pimentel. Extensão universitária no Brasil: uma revisão conceitual. In: FARIA, Dóris Santos de (Org.). Construção conceitual da extensão Universitária na América Latina. Brasília: UNB, 2001. p. 57-72.

OBSERVATORIO IBEROAMERICANO DE LA CIENCIA, LA TECNOLOGÍA Y LA SOCIEDAD (OCTS-OEI); RED IBEROAMERICANA DE INDICADORES DE CIENCIA Y TECNOLOGÍA (RICYT). Manual Iberoamericano de Indicadores de Vinculación de la Universidad con el Entorno Socioeconómico. Valencia, 2017. Disponível em:

http://www.ricyt.org/2017/06/manual-de-indicadores-de-vinculacion-de-la-universidad-con-el-entornosocioeconomico-manual-de-valencial. Acesso em: 10 set. 2019.

ROCHA, Roberto Mauro Gurgel. A Construção do Conceito de Extensão Universitária na América Latina. In: FARIA, Dóris Santos de (org.). Construção conceitual da extensão Universitária na América Latina. Brasília: UNB, 2001. p. 13-29.

STALEY, David J. Democratizing American Higher Education: the legacy of the Morrill Land-Grant Act. Origins: Current Events in Historical Perspective, Columbus, v. 6, n. 4, jan. 2013. Disponível em: https://origins.osu.edu/article/democratizing-american-higher-education-legacy-morrill-land-grant-act. Acesso em: 10 set. 2019.

TÜNNERMANN BERNHEIM, Carlos. El nuevo concepto de extensión universitaria y difusión cultural y su relación con las políticas de desarrollo cultural en América Latina. Anuario de Estudios Centroamericanos, San José, n. 4, p. 93-126, 1978. Disponível em: www.jstor.org/stable/25661648. Acesso em: 13 mar. 2020.

TÜNNERMANN BERNHEIM, Carlos. La universidad ante los retos del siglo XXI. Ciudad de México: UADY, 2003.

UNIVERSITY OF MANCHESTER. Units. Available semesters. Manchester, 2019. Disponível em: http://www.college.manchester.ac.uk/. Acesso em: 10 set. 2019.

UNIVERSITY OF WISCONSIN-MADSON. Community-Based Learning. Madson, 2019.

Disponível em: https://morgridge.wisc.edu/students/community-based-learning/. Acesso em: 10 set. 2019. 
VALLANCE, Paul. The historical roots and development of the civic university. In: GODDARD, John et al. (Ed.). The Civic University: The Leadership and Policy Challenges. Cheltenham, UK: Edward Elgar, 2016. p. 16-33.

WATERS, Susan; ANDERSON-LAIN, Karen. Assessing the Student, Faculty, and Community Partners in Academic Service-Leraning: a categorization of surveys posted online at campus compact member institutions. Journal of Higher Education Outreach and Engagement, University of Georgia, Athens (GA), v. 18, n. 1, p. 89-122, 2014. Disponível em: https://eric.ed.gov/?id=EJ1024168. Acesso em: 14 set. 2019.

WELCH, Edwin. The Peripatetic University: Cambridge Local Lectures 1873-1973. London: Cambridge University Press, 1973. 